\title{
O cenário do ensino de língua inglesa no Brasil: globalização, poder e exclusão social
}

Flávia Cristina Martins de Oliveira (UFBA)*

https://orcid.org/0000-0002-0853-2197

\section{Resumo:}

A globalização está modificando o mundo na distância física, temporal e na perda de fronteiras. Esse fenômeno se realiza no cotidiano por causa da Internet e da língua inglesa. 0 contexto da globalização atual é uma conquista gigantesca para a humanidade. Todavia, ela não atinge a todos. Ela só proporciona essa interação para os que podem adquiri-la, tanto em relação aos aparelhos eletrônicos e na manutenção da Internet, quanto na aprendizagem da língua inglesa. No Brasil, apesar das conquistas na área de línguas estrangeiras através das leis que regem a educação, muito ainda não se tem atingido nas escolas regulares, principalmente as públicas. 0 objetivo de formar cidadãos com um razoável conhecimento de inglês não se concretiza. Neste contexto, o ensino de inglês no Brasil representa uma relação de poder, pois é considerado um produto de consumo. Esse trabalho objetiva analisar propagandas de cursos de idiomas através da análise do discurso crítica. 0 corpus desse estudo foi coletado de sites de cursos de idiomas. No resultado, percebe-se no discurso dos cursos uma ideologia elitista e excludente, com a intenção de manter o status quo da classe média e rica brasileira.

Palavras-chave: Globalização. Aprendizagem de língua inglesa. Análise do discurso crítica. Exclusão social.

\section{Abstract:}

\section{The scenario of English language teaching in Brazil: globalization, power and social exclusion}

Globalization is changing the world in terms of physical, temporal distance and the loss of borders. This phenomenon occurs in everyday life because of the Internet and the English language. The context of current globalization is a gigantic achievement for humanity. However, it does not reach everyone. It only provides this interaction for those who can acquire it, both in relation

* Doutoranda no Programa de Pós-Graduação em Língua e Cultura (PPGLINC) pela Universidade Federal da Bahia (UFBA). E-mail: teacherflafi@gmail.com 
to electronic devices and the maintenance of the Internet, and in learning the English language. In Brazil, despite the achievements in the area of foreign languages through the laws that govern education, much has not yet been achieved in mainstream schools, especially public ones. The objective of forming citizens with a reasonable knowledge of English is not achieved. In this context, teaching English in Brazil represents a power relationship, as it is considered a consumer product. This paper aims to analyze advertisements for language courses through the analysis of critical discourse. The corpus of this study was collected from language course websites. In the result, an elitist and exclusionary ideology is perceived in the course discourse, with the intention of maintaining the status quo of the Brazilian middle and wealthy class.

Keywords: Globalization. English language learning. Critical discourse analysis. Social exclusion.

\section{Introdução}

Esse trabalho discute diferentes vieses do ensino de língua inglesa no Brasil. 0 primeiro viés surge com a implementação e a obrigatoriedade de uma língua estrangeira moderna no ensino básico. Outras leis aparecem depois para sustentar esse ensino nos anos subsequentes e na grande maioria, a opção é pela língua inglesa. (BRASIL, 1996; 1998; 2000; 2006; 2017) O segundo viés surge na contemporaneidade com o fenômeno que modifica a maneira de viver, trabalhar e interagir no mundo, a globalização. Ela demanda a necessidade de se comunicar em inglês para pertencer nesse mundo globalizado. (KUMARAVADIVELU, 2006) A partir dessa lógica é que será discutida a questão da aprendizagem de inglês e a exclusão social, já que como essa aprendizagem geralmente não se efetiva na escola, um terceiro viés se consolida pelo país, os cursos de idiomas.

Nessa conjuntura são observadas as relações de poder na sociedade através da (im)possibilidade de se aprender a língua inglesa. Com o embasamento da análise do discurso crítica, o trabalho analisa o discurso de algumas escolas de idiomas para des- naturalizar essas relações entre as classes sociais brasileiras. (VAN DIJK, 2017; FAIRCLOUGH, 2001; 2003)

0 trabalho está dividido da seguinte maneira: a primeira parte é intitulada Globalização e Exclusão Social, em que será apresentada a força que a Internet e a língua inglesa tiveram para difundir o fenômeno mundial da globalização, tanto para inserir pessoas, como para excluir os que não podem se apropriar dela. A segunda parte, o Cenário do Ensino de Língua Inglesa no Brasil, discutirá a implementação de uma língua estrangeira moderna no país e suas implicações para o ensino básico em escolas públicas e particulares. Na maioria dos casos, a opção pela língua inglesa como língua estrangeira moderna é primeira opção, dada sua relevância na contemporaneidade. A terceira parte apresenta A Análise do Discurso Crítica, seção que mostra questões levantadas por Fairclough $(2001 ; 2003)$ na interação social através da língua e suas relações de poder. (VAN DIJK, 2017) Na análise de dados, intitulada Aprendizagem de Língua Inglesa para Todos? o trabalho analisa o discurso de propagandas de sete 
cursos de idiomas. A última seção, Considerações Finais, traz algumas reflexões sobre as implicações do discurso dos cursos de idiomas para uma sociedade excludente e desigual.

\section{Globalização e exclusão social}

A globalização não é recente, como muitos acreditam. É um processo que vem ocorrendo há mais de 12.000 mil anos. 0 que difere a globalização atual dos ciclos que já ocorreram durante a história da humanidade é a sua intensidade e a interligação cultural e social que as pessoas estão vivenciando na atualidade. (KUMARAVADIVELU, 2006, p. 130, 131)

Existiram três grandes ondas de globalização: a primeira fase foi a do colonialismo/ imperialismo, centradas nas explorações comerciais de Portugal e Espanha, a segunda foi marcada pela industrialização liderada pela Grã-Bretanha e, a terceira ocorreu no mundo pós-guerra, liderada pelos Estados Unidos. Contudo, a globalização atual é diferente da dos outros períodos, pois está modificando o mundo em três aspectos: a distância física, a distância temporal e a perda de fronteiras. Atualmente é possível fazer negócios com pessoas em todos os lugares do planeta, assistir em tempo real acontecimentos que antes só chegavam como notícia depois de dois, três dias, dependendo do lugar e dos recursos do país. Os deslocamentos físicos estão mais rápidos e financeiramente mais acessíveis. Famílias se mudam em busca de novas oportunidades profissionais e de estudo, sem que isso os distancie por anos dos familiares que ficam.

Tudo isso se realiza no cotidiano por causa da Internet. Ela mudou e segue modificando a forma como as pessoas compartilham conhecimento, fazem transações comerciais, relacionam-se e interagem na contemporaneidade. Não há dúvidas sobre o aspecto primordial que essa ferramenta exerce para que a globalização tenha obtido proporções tão grandes.

Outro fator preponderante que impulsionou a disseminação da globalização foi a língua inglesa. É através dela que a comunicação pela Internet majoritariamente acontece. É a língua que proporciona que pessoas de nacionalidades e línguas tão diversas consigam interagir. Pelo seu papel tão significativo na globalização, hoje ela é denominada língua internacional, língua global, e atingiu o status de língua franca contemporânea. (JENKINS, 2006; 2011) Isso pode ser considerado reflexo de seu poder de dominação nos séculos anteriores, onde o inglês se disseminou pelos quatro cantos do planeta em consequência de seu poderio econômico, como explica Kupske (2011, p. 5):

Da história da língua inglesa no Reino Unido, o que nos resta saber no momento é que a Inglaterra foi extremamente bem sucedida no que concerne à expansão colonialista. Nos séculos XVIII, XIX e XX a Inglaterra apresenta um grande poderio econômico impulsionado pela Revolução Industrial. Contudo, esse império de influência política e econômica alcança seu apogeu na primeira metade do século XX, com uma expansão territorial que, em 1921, segundo Pennycook (2004) atingiu algo em torno de $25 \%$ da população mundial, um quarto do planeta estava sobre o domínio do Trono Inglês. O Império Britânico chegou a ficar conhecido como o Império no qual o sol nunca se põe, dada a extensão de seus domínios. Esse sucesso socioeconômico levou, como consequência, ao sucesso internacional da língua inglesa.

0 inglês é a segunda língua mais falada no mundo e há tempos o número de falantes não nativos ultrapassou o de falantes nativos. Hoje existe um falante nativo de língua inglesa para quatro não nativos. A fim de ilustrar a distribuição dos falantes 
de inglês, Kachru (1982; 1985) elaborou os círculos concêntricos. 0 círculo interno é formado por falantes nativos, aqueles que têm o inglês como primeira língua. 0 círculo externo, que envolve o interno, é formado por falantes de inglês como segunda língua, como por exemplo a Índia, que foi colonizada pelos ingleses. 0 último círculo, envolvendo os outros dois, é o círculo em expansão, lugar dos falantes de inglês como língua estrangeira.

Apesar dos círculos concêntricos serem considerados uma estrutura estática, posicionando os falantes em espaços delimitados e restritos, eles foram um excelente referencial nas décadas de oitenta e noventa para compreender essa distribuição dos falantes de inglês ao redor do mundo. Atualmente, com o advento da Internet, com a modernidade líquida (BAUMAN, 2007) e o mundo fluido da pós-modernidade (HALL, 2006), as barreiras estabelecidas pelos círculos estão se diluindo. Hoje a migração é crescente ao redor do planeta, e ser bilíngue é questão de sobrevivência para muitas pessoas. (SCHIMITZ, 2014) Nesse ínterim, ser monolíngue é considerado uma desvantagem, caso dos falantes nativos de inglês. Como explica Jenkins (2006; 2011) e Graddol $(1997 ; 2006)$ o falante nativo acaba se acomodando, pois se o mundo fala inglês, ele não precisa se esforçar, basta falar que todos irão compreendê-lo. Esse raciocínio está equivocado, já que é necessário fazer uma adaptação linguístico-cultural para interagir com falantes de inglês como língua estrangeira. Vários são os fatores que influenciam na comunicação, pois a cultura do falante irá reverberar na sua interação em inglês. 0 intercâmbio de experiências nestes casos pode ser muito profícuo se os falantes estiverem conscientes e dispostos a interagir interculturalmente. (MENDES, 2007)
É a partir do viés apresentado acima que se pode afirmar que o inglês perdeu seu caráter territorial de cunho "americano" ou "britânico", pois hoje ele transpõe barreiras geográficas e pertence a todos os não nativos que fazem uso dele para trabalharem, viajarem, se comunicarem, enfim viverem neste mundo sem barreiras fixas, um mundo versátil, flexível e em constante movimento. (BAUMAN, 2007; HALL, 2006) Steger (2003, p.13 apud Kumaravadivelu, 2006, p. 130) define essas mudanças de cunho social, tecnológico e econômico como:

[...] uma série multidimensional de processos sociais que criam, multiplicam, alargam e intesificam interdependências e trocas sociais no nível mundial, ao passo que, ao mesmo tempo, desenvolve nas pessoas uma consciência crescente das conexões profundas entre o local e o distante.

O contexto da globalização atual é uma conquista gigantesca para o desenvolvimento da humanidade em seu caráter científico, econômico e cultural. Todavia, ela não atinge a todos. Aliás, ela só proporciona essa interação para os que podem adquiri-la, ou seja, possuem capital para financiá-la. Principalmente do lado de cá, no Brasil. Nem todos têm capital para manter Internet e muitos não sabem o mínimo de inglês para interagir.

Junto a isso, depara-se na sociedade brasileira com o imperialismo linguístico, expressão que serve para descrever a força de domínio que uma língua exerce em países que foram colonizados no passado. Pelo poder socioeconômico de alguns países falantes de inglês, juntamente com sua ampla divulgação linguística e cultural desse idioma no mundo, a hegemonia e eurocentrismo da língua inglesa estão arraigados aqui, quer no contexto cultural do brasileiro e de outras ex-colônias, quer no pensamento 
cristalizado de que só o que vem do lado norte do mundo é valorizado e legitimado para o mundo. É o que Santos (2007) denomina de pensamento abissal. Um verdadeiro abismo separa o norte do sul, considerando o norte os países imperialistas e o sul os países que foram colonizados no passado e, muitas vezes, ainda presos na mentalidade subserviente de colonizados. Como Santos (2007) esclarece através da questão da visibilidade e da invisibilidade na contemporaneidade:

0 pensamento moderno ocidental é um pensamento abissal. Consiste num sistema de distinções visíveis e invisíveis, sendo que as invisíveis fundamentam as visíveis. As distinções invisíveis são estabelecidas através de linhas radicais que dividem a realidade social em dois universos distintos: o universo "deste lado da linha" e o universo "do outro lado da linha". A divisão é tal que o "outro lado da linha" desaparece enquanto realidade, torna-se inexistente, e é mesmo produzido como inexistente. Inexistência significa não existir sob qualquer forma de ser relevante ou compreensível. Tudo aquilo que é produzido como inexistente é excluído de forma radical porque permanece exterior ao universo que a própria concepção aceite de inclusão considerada como sendo o Outro. A característica fundamental do pensamento abissal é a impossibilidade da co-presença dos dois lados da linha. Este lado da linha só prevalece na medida em que esgota o campo da realidade relevante. Para além dela há apenas inexistência, invisibilidade e ausência não-dialéctica. (SANTOS, 2007, p. 3, 4)

Enfim, é nesse contexto que se compreende a impossibilidade de ser e de se poder para os que estão na zona de invisibilidade, excluídos das ferramentas que conectam os visíveis no mundo globalizado. Nessa situação estão os que não podem ter uma educação de qualidade para interagir na língua global, o inglês.

\section{O cenário do ensino de inglês no Brasil}

O ensino de idiomas no Brasil surgiu na primeira metade do século vinte. Houve três momentos que marcaram a história do ensino-aprendizagem de línguas no contexto brasileiro. 0 primeiro deles ocorreu com as discussões e a legislação que salientava a importância do ensino de um idioma na educação. No entanto, não havia muitos professores preparados na época e o ensino focava muito no método de gramática-tradução, ocorrendo de forma descontextualizada. 0 segundo momento surgiu na década de setenta com a percepção da elite brasileira de que falar um idioma facilitava o diálogo com estrangeiros em viagens e passeios para o exterior. $\mathrm{O}$ terceiro momento ocorreu com a Lei de Diretrizes e Bases (LDB) de 1996 que incluiu obrigatoriamente o ensino de uma língua estrangeira moderna na grade curricular das escolas a partir da antiga 5a série. Apesar de a escola poder eleger a língua que será lecionada, a opção majoritariamente é pela língua inglesa, devido ao contexto descrito acima. (FRAGOZO; MONAWAR, 2012)

A LDB/1996 foi fundamental para que a educação linguística se estabelecesse no Brasil. Ela obriga que no ensino básico haja uma língua estrangeira obrigatória e uma segunda optativa. Após a LDB, os Parâmetros Curriculares Nacionais (PCN) de 1998 são publicados. Eles oferecem diretrizes para que os professores de todas as áreas tenham maior clareza nos objetivos e competências que devam trabalhar com os alunos. Depois dos PCN, surge os PCN para o ensino médio em 2000, que reitera o primeiro documento, com a diferença de que já compreende que as quatro habilidades linguísticas devem ser contempladas no ensino de línguas estrangeiras na escola regular. Além disso, faz uma 
integração com as áreas de humanas, denominada Linguagens, Códigos e suas Tecnologias. Já as Orientações Curriculares para o Ensino Médio, publicada em 2006, traz uma proposta mais inovadora, com articulação entre as várias áreas de ensino, propondo para a área de línguas uma educação interdisciplinar, com a formação integral do aluno para se tornar um futuro cidadão crítico e reflexivo. Propostas de trabalho como letramento e gêneros textuais são apresentadas nessas diretrizes. A Base Nacional Comum Curricular, instituída em 2017, coloca a língua inglesa como disciplina obrigatória para uma formação integral, além de contemplar multiletramentos, inglês como língua franca e interculturalidade como conceitos que balizam a aprendizagem da língua inglesa na contemporaneidade.

Apesar das grandes conquistas na área de línguas estrangeiras, que estabelecem e fundamentam os objetivos para o ensino, muito ainda não se tem atingido na realidade das escolas regulares, principalmente as públicas. A começar pela estrutura das escolas, pois várias não possuem o básico para uma aula de qualidade, como recursos tecnológicos, por exemplo. A perda de prestígio na área de licenciatura e os desafios que os futuros professores irão enfrentar não tornam a carreira no ensino muito motivante dentre as opções existentes. Particularmente para o ensino de inglês, a falta de material didático adequado e o grande número de alunos dificulta a realização de tarefas que exercitem as habilidades de escuta e fala. Nesta conjuntura das leis e diretrizes discutidas e a realidade da situação da educação no Brasil é que Borges $(2013$, p. 60, 61) corrobora:

[...] As escolas públicas, na Educação Básica, atendem à maioria, recebendo a matrícula daqueles que a procuram. 0 que se anuncia é que há escolas e vagas para todos. Contudo, percebemos que se democratiza o acesso à escola, mas falta a boa qualidade de ensino para todos. Se por um lado, na escola, em nível de Educação Básica, democratizou-se o acesso em nível superior em torno de 90\%, por outro, não há, até o momento, êxito na democratização do acesso ao saber, para todos e todas. A escola não tem conseguido cumprir a sua função de ensinar a toda diversidade de alunos presentes no seu cotidiano.

Destarte, o aluno da escola pública tem como única opção a aprendizagem nas escolas. 0 que geralmente acontece é que, como o ensino público não atinge o objetivo de preparar cidadãos com um razoável conhecimento da língua, o aluno da escola particular recorre às aulas de cursos de idiomas, sejam presenciais, virtuais, formação bilíngue, etc. Nessa linha de raciocínio, pode-se dizer que para sanar um problema que está dentro das escolas, o mundo capitalista cria subterfúgios para resolver a situação, privilegiando somente quem pode pagar. Não à toa, os cidadãos que se comunicam em inglês para viagens, intercâmbios, trabalho, são aqueles que tiveram a oportunidade de cursar o idioma além da escola regular, em sua grande maioria. Isso só corrobora o que Santos (2007) afirma sobre o pensamento abissal contemporâneo e a linha que separa os incluídos e visíveis do mundo capitalista da invisibilidade dos excluídos. Esse questionamento também faz Borges (2013, p. 60) ao interrogar:

Mas e a qualidade das escolas públicas, destinadas às classes menos abastadas, como se encontram dentro da nossa sociedade capitalista, desigual e excludente? E o conhecimento científico e a educação escolar poderão contribuir com a construção de um mundo melhor? Tem sido possível, na prática, viabilizar uma escola inclusiva? 
A exclusão social se solidifica com o passar dos anos, pois a globalização cresce em movimentos ascendentes dentro da nossa sociedade. A criação de gadgets e de recursos tecnológicos cada vez mais avançados acaba por incorporar e integrar a sociedade já global nessa rede interativa e distanciar os excluídos de conquistar tais possibilidades. Nesse ínterim o inglês se torna no Brasil símbolo de poder e de status dentro da sociedade, reflexo de quem pode pagar aulas fora da escola e assim perpetuar a posição do curso de idiomas no país. É o que afirma Gimenez (2011, p. 48) ao dizer que:

À medida que o inglês se torna uma língua de alcance global (GRADDOL, 2006), seu papel na produção e reprodução das relações sociais se altera. Não se trata apenas das possibilidades que a língua inglesa cria e de uma interação em escala mundial, mas também de sua limitação nas próprias fronteiras nacionais. $\mathrm{Na}$ atualidade, o inglês não discrimina apenas porque não permite contato com outras culturas a quem não tem conhecimento da língua, mas também porque dentro do próprio país funciona como um mecanismo de exclusão.

Esse mecanismo fica marcado pelas relações de poder que constituem a sociedade. A hegemonia linguística do inglês, o poderio socioeconômico da Inglaterra e atualmente dos Estados Unidos, o etnocentrismo do poder, do conhecimento, da legitimação da cultura britânica e norte-americana, dos dialetos de prestígio do próprio inglês, enfim, essas relações de poder se construíram e se solidificam também através do discurso nas relações de poder.

\section{A análise do discurso crítica}

A análise do discurso crítica (ADC) é uma abordagem científica que considera a linguagem como discurso, isto é, a materiali- zação da comunicação humana no interior de uma prática social. Nesse viés, o discurso é construído pelas ideologias existentes em um determinado grupo social e essas práticas sociais se balizam pelas relações de poder, representadas pelo discurso que pode controlar, manter e perpetuar situações de hierarquização impostas pela sociedade. (FAIRCLOUGH, 2001; VAN DIJK; 2017)

O termo análise do discurso crítica (ADC) surgiu em um congresso em Amesterdã em 1991. Estavam reunidos nesse encontro Teun Van Dijk, Norman Fairclough, Gunter Kress, Theo van Leeuwen e Ruth Wodak. Todos se reuniram para discutir teorias e métodos em análise do discurso e acabaram cunhando um novo paradigma. Segundo Norman Fairclough (2001; 2003), a ADC é uma abordagem transdisciplinar do estudo de textos, que são considerados todos os gêneros discursivos, tanto orais quanto escritos. 0 discurso, constituído pelo signo linguístico é revestido de ideologia, é abstrato e possui significação, pois carrega consigo marcas sócio-histórica-política-culturais dentro do contexto em que é utilizado. Assim como Fairclough, Bakhtin (2006) defende que na análise do discurso a língua é dinâmica, cheia de valores e varia de grupo para grupo social em que é usada, inclusive entre as classes sociais. Por isso, a língua é viva e funcional e se realiza através de seus falantes, é dialógica e social. Neste viés, as pessoas não trocam sinais, como no postulado Saussureano, mas quando se comunicam, elas dizem verdades, mentiras, mostram surpresa, incredulidade, entre outras que se realizam através dos enunciados linguísticos.

Para a análise do discurso o signo, não apenas reflete, mas também refrata, ou seja, pode ser fiel, apresentar-se de um ponto de vista específico ou distorcer sua significa- 
ção. No último caso isso pode ser percebido no uso da língua por diferentes classes sociais. Destarte, a ideologia revestida na língua das classes de poder geralmente tenta sufocar as classes populares, utilizando os signos abstratos como ferramenta para tal. (BAKTHIN, 2006) Importante ressaltar que ideologia neste contexto para Van Dijk é considerado como um conjunto de ideias construídas e que orientam as práticas sociais de um determinado grupo:

[...] Apesar da variedade de posturas em relação ao conceito de ideologia, pressupõe-se, em geral, que o termo refere-se à "consciência" de um grupo ou classe, explicitamente elaborada ou não em um sistema ideológico, que subjaz às práticas socioeconômicas, políticas e culturais dos membros do grupo, de forma tal que seus interesses (do grupo ou da classe) materializam-se (em princípio da melhor maneira possível). (VAN DIJK, 2017, p. 47)

Nessa conjuntura, a ADC tem como preocupação analisar relações de poder instituídas ideologicamente no discurso quando são consideradas abusivas. Cabe afirmar que essa tentativa de controle através do discurso não se constrói pelo discurso isolado de apenas um sujeito, mas por um grupo que detêm o poder. Van Dijk (2017, p. 21) afirma isso ao dizer que:

[...] Poder nesse sentido não deve ser definido como o poder de uma pessoa, mas antes como o poder de uma posição social, sendo organizado como parte constituinte do poder de uma organização. Portanto, precisamos fazer uma análise social muito mais sofisticada para conseguirmos indicar com precisão quem controla o discurso público e como.

Na ADC necessariamente há relação entre a análise linguística do discurso e a análise da crítica no contexto social que permeia esse texto. Pois a ideologia, que se configura nas relações de poder, está imbricada nos discursos produzidos pela sociedade.

$\mathrm{Na}$ esteira desse pensamento, o contexto do ensino de língua inglesa no Brasil representa uma luta de poder, já que é considerado um produto de consumo. Segundo Fairclough (2001) essa característica do discurso é denominada de comodificação. Sinteticamente, pode-se dizer que é a industrialização de bens culturais e educacionais. A cultura e a educação são colocadas no lugar de produto para que a sociedade possa adquiri-la, e os alunos são considerados clientes. 0 discurso educacional, o motor operante desse mecanismo, apresenta a educação não como um direito de todos, mas como uma posse. A lexicalização nesse processo discursivo é muito importante, pois são as palavras chave que atraem os alunos/ clientes para a escola/universidade/cursos. Dentre elas Fairclough cita "competências" e "habilidades", jargões da área de linguística e linguística aplicada, que acabam atraindo o público alvo para a aquisição do produto "conhecimento".

Sendo assim, a língua inglesa na escola regular pela perspectiva da ADC, fica marcada como a disciplina que não cumpre sua função, pois se transformou em mercadoria, arraigada de uma ideologia de derrota, segundo Siqueira (2011, p. 100):

[...] a mercantilização e/ou "mercadologização" da educação, onde o sucesso de um sistema preconiza a ruína do outro, o discurso que se solidifica dá margem a verdadeiras aberrações que, por exemplo, atribuem a incapacidade dos alunos da escola pública de aprender inglês ou outra LE (língua estrangeira) à condição socioeconômica, déficit linguístico, déficit cultural etc., conferindo ao processo um viés altamente ideológico e de perpetuação de desigualdades [...]

Não só a comodificação do conteúdo é utilizada como um mecanismo discursivo, 
mas também a publicidade na venda de produtos. 0 gênero discursivo publicidade tomou proporções imensas na contemporaneidade, pois cada produto, para alcançar seu público, deve ter uma imagem única que cria uma identidade. E a publicização do discurso educacional tem uma característica muito forte neste contexto. É por isso que esse trabalho propõe analisar as propagandas de cursos de idiomas através da ADC.

\section{Aprendizagem de língua inglesa para todos?}

A partir de todo o exposto acima, surgem inquietações sobre a proposta de ensino de língua inglesa através dos cursos de idiomas. Esses cursos são direcionados para quem? 0 discurso de que a aprendizagem de um idioma não se realiza dentro do ambiente escolar abre lacunas para que outros modelos de ensino surjam e se estabeleçam por causa da ineficiência da escola básica.

Nessa conjuntura, esse trabalho objetiva analisar peças publicitárias de alguns cursos com o embasamento da ADC, a partir de três categorias de análise: o interdiscurso, a seleção lexical e a representação do ator social. 0 interdiscurso analisa a articulação do discurso com outros textos, gêneros e estilos. Essa hibridização discursiva pode apresentar lutas de poder no discurso analisado. Na categoria lexical, o vocabulário escolhido para compor o discurso apresenta pistas importantes sobre a ideologia que constitui o discurso que será analisado. E a representação do ator social está relacionada ao significado representacional e a discursos de pessoas em particular. Nesse tipo de categoria, o ator social pode ser omitido, incluído, ofuscado, enfatizado, etc.

O corpus desse estudo foi coletado de sites de sete cursos de idiomas renomados no Brasil. Os sites cujos cursos foram visitados são Yázigi, CNA, CCAA, Wizard, Wize up, ACBEU e Fisk. O levantamento do corpus foi realizado em novembro de 2018. 0 foco foi na proposta de estudo presencial, já que muitos atualmente oferecem cursos a distância ou com caráter híbrido. Essa escolha se deu por ser a mais semelhante com o momento de aprendizagem escolar. 0 corpus do discurso dos cursos foi organizado da seguinte maneira: o slogan, a proposta das aulas, a metodologia, o material didático, a representação do ator social professor, os argumentos de cada curso para conquistar alunos e a certificação oferecida.

No quesito slogan, os cursos mantêm linearidade em relação a proposta de possibilidades na aprendizagem, dando sentido de que o inglês é um passaporte incontestável para o sucesso. As escolhas lexicais composição dos slogans são: cidadão do mundo (Yázigi), inglês definitivo (CNA), você bilíngue, inglês número um (Wizard), todos falam bem (ACBEU), fale inglês (Wise up), quer ganhar o mundo? Fale a língua dele (Fisk). Observa-se a grande proximidade com o argumento da globalização para propor ascensão no trabalho, oportunidade de viagens, inserção no mundo globalizado, enfim, conquistar o mundo global. E da melhor maneira possível, com uma aprendizagem definitiva, tornando-se bilíngue, a partir de uma associação de ideias que estão subjacentes, pois o aluno pode ser o número um no trabalho, na escola, tendo o melhor inglês, o inglês daquele determinado curso que tem um diferencial.

Em relação à descrição das aulas, quatro cursos descrevem o tipo de aula que ofertam. As outras são ausentes nesse quesito. Do discurso apresentado, percebe-se que os cursos acabam minimizando a relevância do processo de aprendizagem, pois 
propõem um momento descontraído, de diversão, deixando transparecer que o período dedicado à aprendizagem passa rápido, e que o aluno não o percebe. As escolhas lexicais mais relevantes encontradas são: dinâmicas, aprendizagem em um ambiente descontraído (Yázigi), aulas dinâmicas e prazerosas, aprendizado mais rápido e eficaz (Fisk), aprendizagem de forma natural e espontânea (ACBEU), naturalmente (CNA). É compreensível que uma aprendizagem significativa seja muito importante, deve ser relacionada às necessidades do aluno, porém aprender demanda tempo, esforço cognitivo e ressignificação de conteúdos e de experiências de aprendizagem. Indiretamente, esse discurso se contrapõe à aprendizagem escolar, como se no ensino básico aprender inglês fosse um fardo e no curso é inteira diversão.

Ainda referente a seleção lexical, dois cursos usam o argumento de satisfação pessoal e profissional (CCAA), aprendizagem para pessoa que almeja crescimento (Wise up), desfrutar de todas as vantagens e oportunidades que isso lhe oferecerá (CNA). Essas escolhas lexicais ultrapassam o sentido restrito de aprendizagem e apresentam o inglês como forma de realização pessoal e crescimento na profissão. Essa proposta será observada também em outras organizações. A intenção dos cursos é de propor muito mais do que um idioma, é dar ao aluno desenvolvimento, crescimento em outros aspectos de sua vida através da língua inglesa.

No que se refere a metodologia, muito descrita e explicada pelos cursos, porém sem fundamentação teórica nenhuma. As escolhas lexicais são: metodologia única e diferenciada, aspectos culturais globais, mais rápido, passeios ecológicos, festas e projetos culturais fazem parte do apren- dizado (Yázigi), método próprio, original e inovador, exclusivo método interativo (CCAA), metodologia exclusiva de ensino, aprendizado contínuo e simplificado, aspectos pessoais, culturais e acadêmicos, além de liderança e automotivação (Wizard), conteúdo exclusivo, sobre oratória, coaching, negociação, liderança, gerenciamento estratégico, empreendedorismo (Wise up), imitam os acontecimentos da vida cotidiana ( $A C B E U$ ), um método moderno, desenvolve seu potencial e vai ainda mais longe (Fisk). Pode-se perceber que o método é quase sempre exclusivo, único, diferenciado, o aluno aprende a língua sem perceber e ainda aprende mais do que o inglês, desenvolve vários aspectos pessoais. Uma promessa um tanto audaciosa e possivelmente inatingível para quem conhece o processo de aprendizagem de um idioma. É necessário tempo, dedicação, sensibilidade intercultural (MENDES, 2007), motivação e desejo. Além de que, o que os cursos denominam metodologias não são baseadas em estudos da linguística. Pois sabe-se que as metodologias amplamente conhecidas e utilizadas são elaboradas por linguistas e se fundamentam em teorias linguísticas que são desenvolvidas através de muitas pesquisas. (LARSEN-FREEEMAN, 1986; BROWN, 2007)

Na esteira da metodologia vem a proposta do material didático. Dois cursos não mencionam seus materiais didáticos, e os outros cinco seguem praticamente com o mesmo discurso: materiais didáticos próprios (Yázigi), materiais especialmente elaborados pela nossa editora (CCAA), material do aluno tem conteúdo exclusivo e atualizado (Wizard), material didático exclusivo (Fisk). Essas escolhas lexicais, tanto da metodologia quanto do material didático dão o sentido de que ao ingressar 
no curso, o aluno irá pertencer a um universo de exclusividade e de privilégios. A comodificação fica evidente nessas escolhas lexicais, já que a língua inglesa é representada como produto a ser adquirido por quem pode pagar pela exclusividade. (FAIRCLOUGH, 2001)

Considerando a representação de ator social, o professor acaba ficando muito camuflado no discurso dos cursos. Dos sete cursos analisados, apenas quatro citam a papel do professor e não se estendem para apresentar sua função no curso. 0 foco fica na qualificação e no treinamento profissional. A intenção é garantir ao aluno que ele estará sendo conduzido por um professor qualificado. Lexicalmente, o ator social é representado da seguinte maneira: atualizados, formados, exclusivos e passam por constantes atualizações no Brasil e no exterior, equipe pedagógica treinada (Yázigi), o professor será seu guia, acompanhará seu progresso (Wizard), investimento e qualificação do corpo docente e intercâmbio contínuo, profissionais treinados (ACBEU), profissionais altamente qualificados e treinados (Fisk). Enfim, o professor não é o protagonista no processo, ele é mero coadjuvante. Além de que os cursos frisam o aspecto de treinamento, nunca mencionam professores formados na área de Letras, e também não citam o teacher development. (BROWN, 2007) Com o teacher development, os professores se desenvolvem profissionalmente como crítico-reflexivos, atuam conscientes de suas opções em sala de aula, tornam-se professores engajados politicamente, culturalmente sensíveis e embasados pela pedagogia crítica. Diferentemente de professores meramente treinados, que são reprodutores dos manuais dos livros didáticos. Como esclarece Rajagopalan (2003, p.113):
No contexto de ensino e aprendizagem de língua inglesa nos países de periferia, a orientação reprodutivista é imediatista, pois objetiva apenas divulgar a língua e a cultura e os valores associados a ela, de forma mais eficaz e rápida, sem se importar com o custo social que a comunidade 'beneficiária' é obrigada a pagar. Dentro dessa orientação, os aprendizes são agentes inteiramente passivos, pedindo para ser 'moldados' na forma que mais convém aos interesses dos educadores.

Em relação aos argumentos utilizados pelos cursos de idiomas para conquistar o alunado, na categoria do interdiscurso, o mais comum é o tempo em que a rede do curso está no mercado. Esse parece ser um argumento muito convincente, pois com ele está o sentido de experiência, ineditismo, pioneirismo, tradição. Além disso, há nesses argumentos a promessa de ascensão social, pois o aluno poderá fazer parte do mundo globalizado, estará apto a participar do mundo competitivo do trabalho, além de estudar em um curso com padrão de qualidade excelente. As escolhas lexicais encontradas nos cursos, referentes aos anos de funcionamento dos mesmos são 60 anos (Yázigi e Fisk), 40 anos (CNA), 57 anos (CCAA), desde 1941 (ACBEU). As promessas para embarcar em um universo global e competitivo estão presentes em: promover o desenvolvimento das pessoas, transformação como cidadão do mundo (Yázigi), oportunidades em suas vidas profissionais (CNA), alcançar o sucesso (CCAA), invista no seu crescimento pessoal e profissional, promoções, impactar no seu salário (Wise up). Interessante relembrar que todo esse leque de possibilidades só está disponível para aqueles que podem pagar por ele, pois os cursos cobram mensalidade e aquisição de material didático. 
A última categoria do interdiscurso é a certificação que os cursos oferecem. Neste ínterim é relevante mencionar que a língua inglesa tem um poder hegemônico indiscutível para a maioria da população brasileira. A relação colonizador-colonizado é muito forte, pois o que vem do colonizador é legitimado pela sociedade. A língua-cultura inglesa é um produto cobiçado, venerado, copiado e reproduzido almejando-se falar da forma mais semelhante possível da de um nativo falante da língua. Esse é um discurso que vende e que o brasileiro legitima, inclusive desmerecendo o professor de inglês não nativo como sendo um profissional de qualidade questionável, que precisa fazer treinamentos e intercâmbios no exterior para ter seu conhecimento reconhecido e validado. Indo na contramão do que foi discutido anteriormente sobre a natureza global da língua inglesa. Sendo assim, o argumento de uma certificação internacional e, em alguns cursos, rigor ao padrão do Quadro Comum Europeu de Referência ${ }^{1}$ são discursos fortes, oferecendo à classe média exatamente o que ela almeja obter para manter seu status na sociedade. Dentre as opções interdiscursivas apresentadas pelos cursos há: equivalência do seu aprendizado com escolas no exterior (Yázigi), certificado internacional (CNA e Wizard), importantes exames internacionais (CCAA), exame internacional (Fisk).

Além da certificação, é apresentada de forma diluída algumas citações sobre o falante nativo e a força dele como argumento de autoridade no ensino do curso. É a perpetuação do etnocentrismo e do poder hegemônico da língua inglesa dentro do nosso país. Importante salientar que os nativos reconhe-

1 Quadro desenvolvido internacionalmente e padronizado para avaliar a proficiência de uma pessoa em uma língua estrangeira. cidos e legitimados são os falantes de inglês americano e britânico, pois o poder socioeconômico consolida essa relação de poder tanto exógena, nativos americanos e britânicos versus colonizados, e endógena, classe média brasileira frequentadora de cursos de língua inglesa versus pobres que ficam à mercê do ensino de inglês na escola básica. Algumas escolhas lexicais que comprovam isso são: recomendada pelo Governo dos EUA (ACBEU), intercâmbio contínuo de professores com instituições universitárias americanas (ACBEU), todo o áudio usado nos materiais é gravado, em nossos estúdios, por falantes de língua inglesa (CCAA), gravado por nativos da língua (Wise up), desenvolvido por escritores nativos da língua inglesa (CCAA), [...] como se fosse um nativo (CCAA), [...] foi até os Estados Unidos para desenvolver o conteúdo exclusivo com nativos (Wise up).

\section{Considerações finais}

Compreende-se através desse panorama que a responsabilidade da escola básica de ensinar língua inglesa não está sendo atingida. Para sanar essa lacuna no ensino surgem e se consolidam cursos de idiomas com a proposta de ensinar de forma dinâmica, rápida, definitiva e significativa o idioma. Além dessa oferta, a comodificação do discurso fica evidente quando os cursos oferecem cidadania global, ascensão social e profissional, aumento de salário e conhecimentos adjacentes para o desenvolvimento global dos alunos que ingressarem no curso de inglês. Aliás, para aqueles que podem pagar as mensalidades para aprender, situação impossível de ser sustentada pelos alunos que frequentam principalmente a escola pública. Como afirma Oliveira (2011, p. 86), o inglês é um produto almejado e elitizado na sociedade brasileira: 
[...] os cursinhos são bens de consumo da classe média em nosso país. 0 aluno de cursinho tem nesse espaço não apenas um ambiente de aprendizagem, mas um contexto para o compartilhamento de valores de sua classe social, inclusive a própria valorização da LE (língua estrangeira). No espaço público do cursinho, o filho de classe média pode emular o modo de vida da cultura estrangeira, que ele provavelmente admira e à qual aspira. A relação comercial desses aprendizes com esse tipo de escola pressupõe um resultado efetivo na aquisição do idioma. Se essa lógica não operar dentro das expectativas do aluno-consumidor (ou de seus pais), a escola simplesmente irá à falência. Esse é o principal motivo de esse tipo de instituição ser eficaz no que se propõe a fazer.

Percebe-se no discurso dos cursos de idiomas uma ideologia elitista e excludente, com a intenção de manter o status quo da classe média e rica brasileira. Esse discurso reflete-se negativamente no ensino de língua inglesa da escola básica pública, pois a proposta do curso nasce a partir das falhas da escola. Nesse movimento, os cursos suprem a necessidade da elite e deixam os invisíveis desamparados. É o pensamento abissal presente no modus operandi da sociedade brasileira. (SANTOS, 2007) Temse então um círculo difícil de ser quebrado. No final, a aprendizagem de língua inglesa é mercantilizada e mantida pela elite brasileira.

\section{Referências}

BAKHTIN, M. Marxismo e Filosofia da Linguagem. 12a edição. São Paulo: Editora HUCITEC, 2006.

BORGES, M. C. Formação de Professores: Desafios Históricos, Políticos e Práticos. São Paulo: Paulus, 2013.

BRASIL, Ministério da Educação e do Desporto. Parâmetros Curriculares Nacionais - Língua Estrangeira. Brasília: MEC, 1998.
BRASIL, Congresso Nacional. Lei de Diretrizes e Bases da Educação Nacional. Lei 9394 / 1996.

BRASIL. Secretaria de Educação Média e Tecnológica. Orientações Curriculares do Ensino Médio: Linguagens, Códigos e suas Tecnologias. Brasília: MEC, 2006.

BRASIL. Secretaria de Educação Média e Tecnológica. Parâmetros Curriculares Nacionais para o Ensino Médio. Brasília, 2000.

\section{BRASIL. Base Nacional Comum Curricular (BNCC). MEC, 2017.}

BROWN, H. D. Teaching by Principles: An Interactive Approach to Language Pedagogy. Prentice Hall, 2007.

FAIRCLOUGH, N. Discurso e Mudança Social nas Sociedades Contemporâneas. In: FAIRCLOUGH, N. Discurso e Mudança Social. Tradução: Izabel Magalhães. Brasília: Universidade de Brasília, 2001. 316 p.

FAIRCLOUGH, N. Texts, Social Events and Social Practices. In: FAIRCLOUGH, N. Analysing Discourse: Textual analysis for social research. London and New York: Rouledge, 2003. 197 p.

FRAGOSO, C. S.; MONAWAR, M. D. English Teaching and Learning in Brazilian Regular Schools and Language Schools: A Study on Teachers' Beliefs. Journal of Education and Learning; Vol. 1, No. 2; 2012.

GIMENEZ, T. Narrativa 14: Permanências e Rupturas no Ensino de Inglês em Contexto Brasileiro. In: LIMA, D. C. (Org.) Inglês em Escolas Públicas não Funciona? Uma Questão, Múltiplos Olhares. São Paulo: Parábola Editorial, 2011.

GRADDOL, D. The Decline of the Native Speaker. AILA Review 13, 1999, p. 57-68.

GRADDOL, D. The Future of English? London: British Council, 1997.

GRADDOL, D. English Next: Why Global English May Mean the End of English as a Foreign Language. London: British Council, 2006.

JENKINS, J. English as a Lingua Franca: Challenging the 'Standard'. TESOL Annual Convention New Orleans, 2011.

JENKINS, J. Current Perspectives on Teaching 
World Englishes and English as a Lingua Franca. TESOL Quarterly 40.1: 157-81, 2006.

KACHRU, B. B. The Other Tongue. English Across Cultures. Urbana, Ill. University of Illinois Press, 1982.

KACHRU, B. B. Standards, Codification, and Sociolinguistic Realism: The English Language in the Outer Circle. In: Quirk, R. and H. Widdowson, (eds.) English in the World: Teaching and Learning the language and the literature. Cambridge: Cambridge University Press, 1985.

LARSEN-FREEEMAN, D. Techniques and Principles in Language Teaching. New York: Oxford University Press, 1986.

KUPSKE, F. F. Inglês como Língua Global: O que Sabem os Profissionais em TEFL? In: XI Seminário Internacional em Letras, 2011, Santa Maria. Anais de evento INLETRAS. Santa Maria: Unifra, 2011.

KUMARAVADIVELU, B. A Linguística Aplicada na Era da Globalização. In: MOITA LOPES, L. P. (Org.). Por uma Linguística Aplicada Indisciplinar. São Paulo: Parábola Editorial, 2006, p. 129-148.

LIMA, D. C. (Org.) Inglês em Escolas Públicas não Funciona? Uma Questão, Múltiplos Olhares. São Paulo: Parábola Editorial, 2011.

MENDES, E. A Perspectiva Intercultural no Ensino de Línguas: Uma Relação "Entre-Culturas". In: ALVAREZ, M. L. O.; SILVA, K. A. da (Org.). Linguística Aplicada: Múltiplos Olhares. Campi- nas (SP): Editora Pontes, 2007.

OLIVEIRA, R. A. A Matrix da LE no Brasil: A Legislação e a Política do Fingimento. In: LIMA, D. C. (Org.) Inglês em Escolas Públicas não Funciona? Uma Questão, Múltiplos Olhares. São Paulo: Parábola Editorial, 2011.

RAJAGOPALAN, K. Linguística Aplicada: Perspectivas para uma Pedagogia Crítica. In: RAJAGOPALAN, K. Por uma Linguística Crítica: Linguagem, Identidade e a Questão Ética. São Paulo: Parábola Editorial, 2003.

RAMALHO, V.; RESENDE, V. de M. Análise de Discurso (para a) Crítica: O Texto como Material de Pesquisa. Campinas, SP: Pontes Editores, 2011.

SANTOS, B. S. Para Além do Pensamento Abissal: Das Linhas Globais a uma Ecologia de Saberes. Revista Crítica de Ciências Sociais, 2007.

SCHMITZ, J. R. Looking under Kachru's (1982, 1985) Three Circles Model of World Englishes: The Hidden Reality and Current Challenges. Revista Brasileira de Linguística Aplicada. Belo Horizonte Apr/June 2014.

SIQUEIRA, D. S. P. O Ensino de Inglês na Escola Pública: Do Professor Postiço ao Professor Mudo, Chegando ao Professor Crítico-Reflexivo. In: LIMA, D. C. (Org.) Inglês em Escolas Públicas não Funciona? Uma Questão, Múltiplos Olhares. São Paulo: Parábola Editorial, 2011.

VAN DIJK, T. A. V. Discurso e Poder. $2^{a}$ ed. São Paulo: Contexto, 2017.

Recebido em: 30/03/2020

Aceito em: 08/06/2020 